\section{The Politics of Political Science: Re-Writing Latin American Experiences ${ }^{*}$}

Diego Fernando Martínez Vallejo

La Política de la Ciencia Política de Paulo Ravecca ofrece un magnífico análisis sobre varios puntos fundamentales dentro de la institucionalización de la ciencia política y su epistemología. En primer lugar, el autor indaga sobre la intersección que existe entre política y conocimiento político, incluso si este último se presenta como científico. Segundo, Ravecca debate sobre la idea de que la institucionalidad de la ciencia política surge y se desarrolla en contextos democráticos, lo cual se pone en cuestión. Tercero, a partir de un análisis autoetnográfico, el autor expone las maneras como se manifiestan y se perpetúan las desigualdades de poder en la ciencia política. Dentro de este último punto, se analizan las implicaciones del régimen político en la vida de quienes enseñan, se instruyen y se forman en ciencia política, así como también la homofobia persistente tanto en la epistemología de la ciencia política como en las prácticas internas de su propia comunidad. El libro de Ravecca es, en esencia, novedoso tanto en los temas que aborda como en su aproximación metodológica: un análisis comparado que triangula con investigación autoetnográfica, una forma poco convencional en la investigación social.

En cuanto al primer punto, a lo largo del libro, Ravecca analiza la política de la ciencia política; entendiendo la primera desde un amplio espectro, no solo el estudio de las relaciones que se establecen entre gobernantes y gobernados, sino también las relaciones de poder que incluso existen en la cotidianidad de las personas y que se ven reforzadas por la misma dinámica inherente del desarrollo del Estado nación. En palabras del autor (2019, p. 173), lo político es personal porque la política afecta vidas; además, agrega que lo político siempre es personal: son las vidas de las personas las que están en juego y se ven afectadas por las decisiones públicas (p. 107). En concordancia con estas observaciones, Ravecca fija su estudio tanto en el análisis de las relaciones de poder que emergen entre Gobierno y academia -y cómo esta última modifica sus discursos y prácticas de acuerdo con la política de su contexto- así como también en la manera en que la política incide, debido a las asimetrías de poder existentes, en las dinámicas internas que ocurren dentro de la misma comunidad científica. Este último punto es analizado desde la propia vida del autor en uno de los capítulos finales de su libro al que denomina "capítulo caliente".
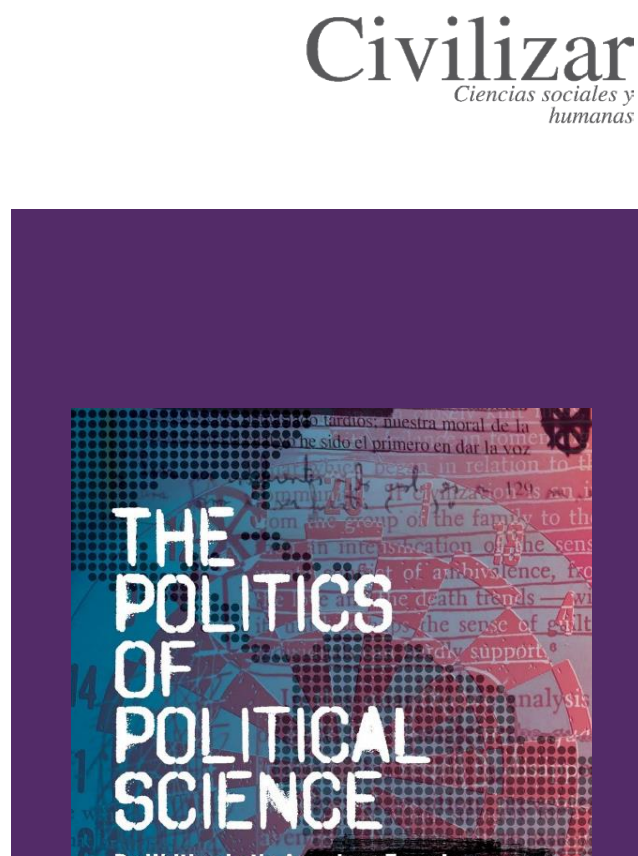

Re-Writing Latin American Experiences

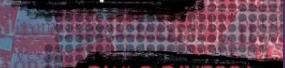

PAULO RAYECCA

I.
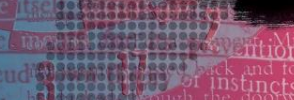

Reseña

Título original:

The Politics of Political Science:

Re-Writing Latin American

Experiences

Autor: Paulo Ravecca

Año de publicación: 2019

Edición: Primera

Páginas: 292

ISBN: 978-081-536308-8

Editorial: Routledge

${ }^{\S}$ Doctor en Ciencia Política de la Universidad Autónoma de Barcelona

y Profesor Asociado de la Escuela de

Política y Relaciones Internacionales de la Universidad Sergio Arboleda,

Colombia.

Correo electrónico:

diego.martinez@usa.edu.co

(iD) $0000-0001-8598-6013$ Atribución-NoComercial- 
La política de la ciencia política es analizada con los lentes de la teoría crítica, muy cercana a la Escuela de Frankfurt. Particularmente, Ravecca toma de ella el desafío a las formas de conocimiento que reifican las relaciones de poder a nivel del pensamiento (Ravecca, 2019, p. 21). Son varias las ideas que emergen dentro de esta escuela; sin embargo, Ravecca presta especial atención al concepto de racionalidad tecnológica de Marcusse, el cual vincula el positivismo con un tipo de racionalidad que elimina del conocimiento científico el debate político (Ravecca, 2019, p. 21). De la teoría crítica, Ravecca también analiza la intersección entre psicoanálisis y marxismo. Frente al primero, reafirma el compromiso con el pensamiento crítico y la subjetividad en la construcción del conocimiento, mientras del segundo toma la idea de que la ciencia no es ahistórica y está condicionada por factores sociales -en Marx, particularmente, ello se verá concretizado en la crítica a la Economía Política, tanto en El Capital como en varias de sus obras previas-.

En cuanto al segundo punto, Ravecca cuestiona la tesis de que la institucionalización de la ciencia política surge y se desarrolla en contextos democráticos (Altman, 2005). Ravecca demuestra, a partir de un estudio comparativo entre Chile y Uruguay, que esta idea no se comprueba plenamente en América Latina. El caso chileno es fascinante ya que ejemplifica que la institucionalización de la ciencia política se da, de hecho, en un contexto autoritario: la dictadura de Augusto Pinochet (1973-1990), lo cual lleva al autor a introducir un concepto novedoso al que denomina Ciencia Política Autoritaria (APS, por sus siglas en inglés). Por ejemplo, la Universidad de Chile comenzó a ofrecer la maestría en Ciencia Política en 1982, durante el gobierno pinochetista. A su vez, las revistas Política y Revista de Ciencia Política -ambas de gran importancia en la academia chilena- fueron también fundadas dentro de dicho periodo autoritario: 1979 y 1982, respectivamente. Para el caso de Política, la revista incluso contó con la aprobación y el visto bueno del dictador Pinochet. Adicionalmente, la productividad de ambas revistas -un indicador sólido de institucionalización- fue mayor en el período dictatorial que en los años posteriores a la transición democrática (Ravecca, 2019, p. 54).

Cabe destacar que, además, dicha proliferación de artículos estuvo enmarcada dentro de un contexto de Guerra Fría, en el que el gobierno chileno mostró clara simpatía por los Estados Unidos. Tal simpatía se vio reflejada también en el contenido de los artículos publicados: mientras varios señalaban explícitamente su inclinación por los Estados Unidos, ninguno se mostraba afín a la Unión Soviética. En general, los artículos dejaban entrever un sentimiento anticomunista persistente, en concordancia con el gobierno, así como también una defensa férrea a la democracia, que a su vez se pensaba como incompatible con el comunismo. La experiencia traumática del gobierno de Unidad Popular y las amenazas provocadas por la Guerra Fría significaron que la nueva democracia chilena tendría que ser defendida contra sus enemigos internos y externos, el comunismo y otros proyectos políticos radicales (Ravecca, 2019, p. 55). Ahora bien, ¿qué tipo de democracia prevalecía en los discursos de los artículos publicados? La democracia que se propugnaba no apuntaba a una de tipo liberal y pluralista, sino más bien a una que defendía la restricción de ciertos derechos y libertades civiles: lo que hoy se conoce como democracia protegida. En este sentido, la restricción de la libertad era necesaria porque, de lo contrario, el exceso de libertad resultaría peligroso para la misma estabilidad y consolidación democrática (Ravecca, 2019, p. 55).

Para el caso uruguayo, si bien la institucionalización de la ciencia política sí se produce durante la transición democrática -contrario al caso chileno-, la dictadura militar (1973-1985) marcó un legado importante en la trayectoria de la ciencia política del país. Trece años de autoritarismo dejaron un sentimiento antimarxista generalizado y una apología reiterada hacia el respeto a la democracia, aunque concebida desde un sentido muy restringido -casi meramente electoral-. Las razones de ello, expone Ravecca, son varias. Primero, la dictadura fue especialmente represiva con el sindicalismo y los partidos políticos de izquierda y con intelectuales y académicos de las ciencias sociales considerados sospechosos y simpatizantes del marxismo (Ravecca, 2019, p. 103). Segundo, la dureza de la dictadura condujo a que los académicos y científicos sociales apreciaran -como nunca antes lo habían hecho- el Estado de derecho y, consigo, la idea de que ningún individuo esté sujeto a las arbitrariedades del gobierno (Ravecca, 2019, p. 106).

La dictadura uruguaya fue lo suficientemente efectiva en la despolitización de la academia, incluso en las ciencias sociales. El conocimiento impartido en las universidades debía enfocarse en la utilidad pragmática y técnica de la ciencia, y de ninguna 
manera en el cuestionamiento del poder político. Bajo esta lógica, la institucionalización de la ciencia política uruguaya a mediados de la década de los ochenta coincidirá con el fortalecimiento de dos grandes áreas. Primero, una valoración y entusiasmo inusitado por la política pública, una rama bastante tecnificada dentro del conocimiento politológico. Segundo, un acentuamiento de los estudios sobre democracia, enfocados, sobre todo, al entendimiento del comportamiento electoral y los sistemas de partidos. La ciencia política uruguaya, en este sentido, se mostraba como protectora de la democracia instrumental, a su vez que imposibilitaba el socialismo y el marxismo, del que propugnaba por su detoxificación (Ravecca, 2019, p. 111). Esta sobrevaloración del conocimiento científico e instrumental se vería pronto reflejada, igualmente, en la forma como se escribe en ciencia política, ya que se pasó de una escritura ensayística -denominada despectivamente por muchos como ensayismo- a una científica que se mostraba como neutral y sistemática.

Las diferencias entre Chile y Uruguay son, con todo, notorias. Por ejemplo, contrario a Chile, el neoliberalismo sigue sin penetrar en Uruguay, ni en la política ni en la ciencia política, al menos no cuando se piensa al neoliberalismo desde su sentido más ortodoxo. La mayoría, de hecho, sigue apoyando la intervención del gobierno en la economía. Parafraseando a Ravecca (2019, pp. 142-143), ni siquiera los académicos más liberales de Uruguay pedirían menor presión fiscal y menor gasto público. Lo anterior se evidencia al analizar los artículos de la revista de ciencia política más importante del país: la Revista Uruguaya de Ciencia Política. Entre 1987 y 2012, solo el $2 \%$ de los artículos promovían reformas liberales, en contraste a las constantes referencias al 'estatismo' que abarrotan la investigación y la prensa uruguaya.

Finalmente, en el "capítulo caliente" y a partir de sus propias experiencias de vida, Ravecca reflexiona sobre la política en la vida familiar, académica y sexual de los individuos, quienes se enmarcan en una dinámica compleja que incluye no solo las dinámicas propias del Estado nación actual, sino también las desigualdades de poder internas. La dictadura, por ejemplo, repercute no solo en la vida de los individuos que experimentan las atrocidades asociadas a ella, sino también en todo aquel que la conoce gracias a las narrativas de las personas que le rodean -incluso si no se ha tenido una experiencia directa, como sucede con las nuevas generaciones-.
Ello es así porque las dictaduras cambian la manera como se estructuran muchas esferas de la vida de las personas, entre ellas, la familia, la sexualidad y la educación y la enseñanza.

Con respecto a esto último y tomando el caso uruguayo, en donde se ubica la infancia y adolescencia de Ravecca, la transición democrática coincide con una ciencia política que reproduce un discurso "objetivo", en el que no existe lugar para las pasiones, el trauma y el poder (Ravecca, 2019, p. 176). Este discurso, afín al legado dictatorial, es conveniente para el mantenimiento del statu quo, ya que relega las teorías amenazantes a un segundo plano e invisibiliza las experiencias de vida de los individuos y, con ello, su gran potencial transformador: la definición misma de política que tiene la ciencia política convencional y que ha sido importada críticamente por la academia uruguaya es violenta, exclusiva e invisibiliza las experiencias dolorosas de muchos (Ravecca, 2019, p. 179).

En el capítulo caliente, Ravecca también devela la homofobia que persiste en la ciencia política. Esta parte del libro es, en mi opinión, fascinante. En primer lugar, esta sección se escribe con un tono muy personal que conduce al lector a un proceso empático en el que se percibe dolor, pero también esperanza. En segundo lugar, proviene de un insider: un hombre homosexual y queer formado en ciencia política. Ravecca sostiene aquí que la ciencia política es homofóbica, y lo es tanto en el campo teórico como en el práctico.

En cuanto a lo primero, la teoría politológica ortodoxa rara vez toma la sexualidad como un objeto de estudio. En los estudios sobre la democracia -el tema de mayor arraigo en la ciencia política- la sexualidad era, hasta hace poco, innombrable ${ }^{1}$. En la práctica, la ciencia política también es homofóbica, y no solamente lo es porque sus miembros reproducen discursos y acciones violentas hacia gais y lesbianas -narrados con dolor por el propio Ravecca-, sino también porque silencia la trayectoria de vida de hombres y mujeres homosexuales que han sido parte integral del desarrollo del conocimiento politológico, como es el caso del uruguayo Carlos de Azúa, uno de los promotores de la institucionalización de la ciencia política de su país. Sin desvalorar los capítulos previos del libro -que en su conjunto develan puntos importantes en la institucionalización y el desarrollo de la ciencia política, y que indudablemente sirven como material de debate para 
futuras investigaciones-, esta parte del texto tiene un aporte invaluable, ya que nos obliga a reflexionar sobre un hecho que es, a mi parecer, claro a todas luces en nuestra disciplina, pero del que nadie habla y nadie escribe. ¡Paulo Ravecca lo hizo!

\section{Referencias}

Altman, D. (2005). La institucionalización de la ciencia política en Chile y América Latina: una mirada desde el sur. Revista de Ciencia Política, 25(1), 3-15.
Inglehart, R. y Wezel, C. (2005). Modernization, cultural change, and democracy. The human development sequence. Cambridge University Press.

Ravecca, P. (2019). The Politics of Political Science: ReWriting Latin American Experiences. Routledge.

\section{Notas}

1 Una excepción, sin embargo, se presenta en Inglehart y Wezel (2005), uno de los textos contemporáneos más citados en Ciencia Política. 